\title{
EL TEMA DE LOS UNIVERSALES EN JUAN DE SALISBURY
}

\author{
César Raña Dafonte \\ Universidad de Santiago de Compostela
}

\begin{abstract}
RESUMEN
Este trabajo presenta la información que Juan de Salisbury nos ofrece en su Metalogicon sobre el problema de los universales en el siglo XII. Se detiene de modo especial en la solución de Aristóteles, por el que muestra gran simpatía.
\end{abstract}

Palabras clave: Juan de Salisbury, Metalogicon, universales, siglo XII.

\begin{abstract}
This work presents the information that John of Salisbury provides us in his Metalogicon about the problem of the universals in the $12^{\text {th }}$ century. He is especially careful when he treats Aristotle's solution, philosopher for whom hi shows great admiration.
\end{abstract}

Key words: John of Salisbury, Metalogicon, universals, $12^{\text {th }}$ century.

Juan de Salisbury (1115-1180) es un testigo muy cualificado de la actividad intelectual del siglo XII, que estaba muy ligada a las escuelas. Pues bien, muestro autor conoció personalmente las principales escuelas así como a los grandes maestros del momento. Nos informa que: «Siendo todavía un adolescente emigré a las Galias para estudiar [...], y me dirigí primeramente al Peripatético Palatino [P. Abelardo (1079-1142)], eminente doctor en Santa Genoveva que destacaba sobre todos. Allí, a su lado, recibí la primera instrucción de dialéctica, y con avidez escuchaba todo lo que decía [...]. Después teniendo en cuenta mis aptitudes, y consultando a mis preceptores me trasladé a estudiar con el gramático de Conches [Guillermo de Conches (1080-1145)], y fui su oyente durante tres años. [...]. Dada mi precaria economía, varios amigos me facilitaron poder subsanarla impartiendo clases a hijos de nobles [...]. Después del trienio me encontré con el maestro Gilberto [Gilberto Porretano (1076-1154)], con él estudié la lógica y la teología [...]. De este modo estuve ocupado en mis estudios durante doce años».' Este breve testimonio entresacado de un famoso capítulo autobiográfico del Metalogicon nos confirma lo que dejamos consignado. En los

1 Metalogicon, II, 10 (PL, 199, 867B-869A). 
años de estudio de Juan las principales escuelas estaban ubicadas en Francia. Precisamente allí estudió durante muchos años.

Otro dato significativo es que el saresberiense no fue docente, «magister» (sólo dio clases particulares algunos años), lo cual no fue bbice para que realizase una tarea como escritor del mayor interés. Sus obras destilan belleza literaria, y son de un inapreciable valor informativo, sobre todo las dos magnas: Policraticus y Metalogicon. El hecho de que no haya sido docente, (por otra parte, conocía muy bien a muchos docentes), le libra de corporativismo a la hora de juzgar la actividad y las cualidades de los maestros de su época. Son muy interesantes sus sugerencias y críticas pedagógicas;

En el siglo XII estaba en plena actualidad el tema de los universales. Este problema que tiene sus raíces en la filosofía griega, y que en nuestros días también tiene ramificaciones, era especialmente atractivo y apasionante en la Edad Media, sobre todo en el siglo XII, pues tenía connotacio nes filosóficas, teológicas y sociales. Por ello no es extraño que nuestro autor, testigo excepcional de la actividad escolar del siglo, sea uno de los mejores informadores sobre el problema citado. En esto nos vamos a centrar en lo que sigue. Pero, antes de detenernos en su información pormenorizada sobre los universales, señalo dos referencias, que aunque esporádicas, son muy significativas. Las dos son de carácter general. Una de ellas aparece siempre que enumera una serie de problemas irresolubles, y que se discutían en las escuelas; entre ellos se menciona explícitamente el de los universales. Esta lista la relata en tres o cuatro ocasiones, al menos. A título de ejemplo recojo el siguiente pasaje: «Para el sabio existen cuestiones dudosas que ni la autoridad de la fe o de los sentidos ni la de una razón manifiesta llegan a disipar, por apoyarse en razones de una y otra parte. Tales son las que se investigan acerca de la providencia; de la sustancia, la cantidad, fuerzas, eficacia y origen el alma; del hado y la disposición de la Naturaleza; de la casualidad y el libre albedrío; de la materia, movimiento y principio de los cuerpos, del progreso de lo plural y de la división de la magnitud; sobre si no tienen límites en absoluto o sólo aquellos que son inaccesibles a la razón; del tiempo y el lugar; del número y la elocución; de lo mismo y lo diverso, donde hay abundantes fricciones; de lo divisible e indivisible; de la sustancia y forma de la voz; de la entidad de los universales [...]\%, Y la lista de las cuestiones dudosas continúa La segunda alusión de carácter general es un tanto irónica, pero muy indicativa. Juan se está refiriendo a un aprendiz osado, y escribe: «Expone una nueva opinión sobre los géneros y especies que pasó inadvertida a Boecio y que no conoció el docto Platón, y que él, por feliz coincidencia, encontró poco antes en los recónditos escritos de Aristóteles. Se encuentra preparado para resolver la antigua cuestión, en la que envejeció el mundo trabajando; en la que se ha consumido más tiempo que cl que tardó la casa del César en adquirir y regir el imperio del orbe y en la que se ha gastado más dinero del que poseyó Creso en todas sus riquezas. Porque ella ocupó durante tanto tiempo a muchos, que buscando sólo eso en toda su vida, finalmente no encontraron ni eso ni otra cosa. Porque así como se busca vanamente en la sombra de cualquier cuerpo la sustancia de una solidez, así en aquellas cosas que sólo son inteligibles y se pueden concebir universalmente, pero no pueden existir como tales, tampoco puede hallarse la sustancia de una existencia más sólida. Pasar la edad en estas cosas es propio de 
quien no hace nada y de quien trabaja en vano, porque son nubes de realidades fugaces, que mientras con más avidez se buscan, con más velocidad desaparecen»."

La información detallada sobre los universales se encuentra en dos capítulos del libro segundo del Metalogicon, en concreto los capítulos 17 y 20 . Serán los que tendré en cuenta. Antes de adentramos en la explicación del problema, conviene subrayar el horizonte en que se mueve nuestro autor. Tiene en cuenta y conoce bien la información de Boecio sobre el tema, el cual, a su vez, se basa en la Isagogé de Porfirio a la que comenta en dos ocasiones. Por ello las resonancias de estos autores son claras. Por otra parte, en su época, este problema era afrontado por todos los maestros de dialéctica, entre los que destacan Pedro Abelardo (sobre todos), y Gilberto Porretano. Las principales exposiciones sobre el problema en cuestión están latentes en lo que escribe e informa Juan de Salisbury.

El capítulo 17 del libro II del Metalogicon se titula: «Quam pemiciose doceatur et quae fuerint de generibus et speciebus opiniones modernorum $\gg .{ }^{4}$ Las primeras palabras del título, como se aprecia, hacen alusión a la docencia inadecuada, de modo especial, en lo referente al problema de los universales. Por ello hace unas advertencias de tipo pedagógico sumamente interesantes: «Muchos maestros tienen una metodología de enseñanza totalmente desafortunada. Pretenden hablar de cualquier problema y del modo más abstruso, sin tener en cuenta a sus alumnos, buscando tan sólo la propia ostentación, y así no se privan de hablar de los temas más difíciles ante principiantes inexpertos que en modo alguno los entienden. Sin embargo, una pedagogía adecuada exige claridad, brevedad y sencillez, adaptándose con todo empeño al discente ( Nostri vero ad ostentationem scientiae suae sic suos istituunt auditores ut non intelligantur ab eis [...]. Sed nunc non erat his locus, cum oratio simplex, res brevis, et facilis quantum potest debeatur introducendis») $\gg .{ }^{5}$ Estas advertencias tienen especial aplicación al explicar el tema de los universales, pues, recordando lo que afirmó Porfirio, en la exposición de los universales a principiantes se han de omitir los temas de fondo más sutiles, pues se trata de algo dificilísimo. Sin embargo, advierte Juan, nuestros maestros no tienen en cuenta tal sugerencia, faltando a las reglas pedagógicas elementales («Naturam tamen universalium hic omnes expediunt, et altissimum negotium et maioris inquisitionis contra mentem auctoris explicare nituntur»). ${ }^{6}$ Una vez hechas estas advertencias pedagógicas, nos informa, con cierto detalle, de las opiniones que sobre los universales se discutieron en el siglo XII. Y, dado que las disputas principales a lo largo de aquel siglo fueron entre realistas y antirrealistas, la exposición del Saresberiense se cifra en las modalidades que se daban en ambas tendencias. Comienza por el antirrealismo. Entre los que niegan la realidad de los universales (es decir, los universales no son «res») menciona las siguientes:

3 Policraticus, (cit.), VII, 12, pp. 540-541.

4 Metalogicon, II, 17. En lo sucesivo citaré esta obra por la edición de J. P. MINGE, Patrologia Latina, con las siglas PL, indicando el volumen y las columnas. Tendré también en cuenta la edición crítica del Metalogicon de J. B. HALL, Brepols, Turnholi. 1991, II, 17, pp. 80-82, en CORPUS CHRISTIANORUM, CONTINUATIO MEDIEVALIS, Vol. XCVIII (Esto mismo vale para lo relativo al capitulo 20 del libro II del Metalogicon, en la edición crítica, pp. 85-100).

$5 P L, 199,874 \mathrm{AB}$.

$6 P L$, Ib. 874 B. 
a) El verbalismo extremo, que niega cualquier realidad, pero incluso un significado consistente, a los términos universales. Son meras emisiones de voz. Nos aclara que esta opinión era la de Roscelino de Compiègne (1050-1120), y que en su época ya estaba obsoleta («Alius ergo consistit in vocibus, licet haec opinio cum Roscelino suo, fere omnino iam evanuerit»). ${ }^{?}$

b) El nominalismo, según el cual los universales son «sermones», es decir, palabras que tienen un contenido significativo, y por ello son términos que se pueden aplicar a muchas cosas. Esta opinión se la atribuye expresamente a su maestro Pedro Abelardo, por quién sentía un gran afecto y admiración. La postura ha tenido muchos seguidores y todavía tiene partidarios. («Alius sermones intuetur [...]. In hac autem opinione deprehensus est Peripateticus Palatinus Abaelardus noster, qui multos reliquit, et adhuc quidem aliquos habet professionis huius sectatores et testes. Amici mei sunt $\gg)^{8}$

c) El conceptualismo. Los universales son conceptos aplicables a muchos individuos. No atribuye expresamente a ningún autor de su época esta opinión pero podría hacerlo a Abelardo, pues el término significativo es la expresión del concepto («Alius versatur in intellectibus, et eos dumtaxat genera dicit esse et species [...]. Notio est quidam intellectus, et simplex amimi conceptio [...]. Eo ergo deflectitur quicquid scriptum est, ut intellectus aut notio universitatem universalium claudat $\gg)^{9}$

Una vez consignadas las soluciones antirrealistas, se centra en el realismo y sus modalidades («Eorum vero qui rebus inhaerent, multae sunt et diversae opiniones»). ${ }^{10}$

a) El realismo. Es la opinión de aquellos que afirman que los universales son realidades, no separadas de los individuos, sino que existen en las cosas particulares, de tal forma que en todos los individuos de una especie, hay una realidad esencial (numéricamente una) que existe en todos y cada uno. Lo mismo pasa con los conceptos genéricos, indican algo que se realiza en todas las especies del género («Siquidem hic ideo quod omne quod unum est, [unum] numero est, rem universalem aut unam numero esse aut omnino non esse concludit. Sed quia impossibile est, substantialia non esse existentibus his quorum sunt substantialia, denuo colligunt universalia singularibus quod ad essentiam unienda»). ${ }^{11}$ De esta opinión dice que no tiene seguidores en su época ( $«$ Sed pridem nullus hanc profitetur»). ${ }^{12}$ Efectivamente, el siglo XII vio declinar la defensa del realismo exagerado.

B) Ultrarrealisno. Siguiendo a Bernardo de Chartres, hay quien defendió que los universales son las ideas ejemplares de las cosas. Esto estaría en la línea del ultrarrealismo platónico, pero en estos momentos nadie admite la subsistencia de las ideas separadas, sino que existen en la mente divina ( «Ille ideas ponit, Platonem aemulatus, et imitans Bernardum Carnotensem, et nihil praeter eas genus dicit esse vel speciem [...]. Est autem idea [...], eorum quae natura fiunt exemplar aeternum»). ${ }^{13}$

$7 P L, 199,874 \mathrm{~B}$.

8 PL, Ib. 874 C.

9 PL, Ib. 874 D.

$10 P L$, Loc. cit.

$11 P L$, Ib., 874 D-875 A.

$12 P L, \mathrm{Ib}, 875 \mathrm{~A}$.

$13 P L, I b ., 875$ A. 
C) Realismo moderado. Esta postura que será defendida con profusión en el siglo XIII, especialmente por Tomás de Aquino, ya tiene partidarios en el siglo XII. Según esta opinión los universales (géneros y especies) no son realidades, pero sí tienen un fundamento real sólido, tal es la forma de todas las cosas de una misma especie, que aunque no es una numéricamente, es decir, cada individuo tiene su forma particular, es, no obstante, exactamente igual en todos los de la especie. Por abstracción de la materia nos quedamos con la forma, fundamento del concepto universal. Esta tendencia se la atribuye a Gilberto Porretano, obispo de Poitiers, cuando escribe el Metalogicon (Juan, en su juventud, había sido alumno de Gilberto), la terminología de Gilberto era la siguiente: la universalidad se basa en las «formas nativas». Las formas nativas son los ejemplares divinos («formas puras») realizados en las cosas materiales. Estas formas nativas son particulares de cada cosa, pero iguales en todos los individuos de una especie, he ahí el fundamento real de los conceptos universales. («Alius [...], cum Gilleberto episcopo Pictavensi, universalitatem formis nativis attribuit, et in earum conformitate laborat. Est autem forma nativa, originalis exemplum, et quae non in mente Dei consistit, sed rebus creatis inhaeret [...]. Sensibilis quidem in re sensibili, sed mente concipitur insensibilis. Singularis quoque in singulis, sed in omnibus universalis»). ${ }^{14}$

Estas son las principales posturas que señala nuestro autor, relacionadas con el realismo. Todavía hace alusiones a otras, pero que considera de menos relieve, pues tan sólo las menciona. De todas formas, escribe que está muy lejos de querer discutir todas las posturas sobre los universales («Longum erit et a proposito penitus alienum, si singulorum opiniones posuero vel errores, cum ut verbo comici utar, fere quot homines tot sententiae» ${ }^{15}$ ). Sería caer en lo que trata de corregir. Pues considera que estas discusiones suponían una carga insoportable e innecesaria para los estudiantes («onera importabilia teneris auditorum imponunt humeris»). ${ }^{16} \mathrm{Y}$, asimismo, advierte que es absurdo envejecer en las escuelas dándole vueltas a esa eterna cuestión, cuando hay otras muchas que deben suscitar la atención de los estudiosos («Et aliis articulis aeque necessariis scitu, locum inquisitionis esse non sinat»). ${ }^{17}$ Después de esta presentación panorámica en el capítulo 17 del libro II de Metalogicon, se va a detener monográficamente en la solución aristotélica al problema de los universales, en el capítulo 20.

El título del capítulo 20 del libro II es el siguiente: «Sententia Aristotilis de generibus et speciebus circumvalata rationibus multis et multarum testimonio scripturarum». ${ }^{18}$ Este capítulo es muy interesante, incluso bastante extenso comparado con otros muchos de la obra. De todas formas tan sólo subrayaré lo relacionado con la solución aristotélica al problema de los universales. Al mismo tiempo pondré de manifiesto la gran sintonía de Juan con esta solución, que la asume como propia.

Ante todo establece que, según el Estagirita, los universales no son realidades, sino meros conceptos, por tanto es claramente antirrealista ( Hic [Aristotiles] genera et species, non esse, sed intelligi tantum asseruit»). ${ }^{19} \mathrm{E}$ insiste que es antiaristotélico todo aquel que defiende el realismo de los 
universales («Qui autem ea [universalia] esse statuit, Aritotili adversatur»). ${ }^{20}$ Por otra parte, aclara que según Aristóteles los universales se forman por la capacidad abstractiva del entendimiento, que basándose en cosas concretas iguales en su esencia, puede obtener un concepto común prescindiendo de las características individuales (así del análisis de varios hombres concretos, abstrae el concepto «hombre»). Esto no falsea la realidad, sino que la considera de otro modo. («Hoc autem naturae rerum non adversatur, quae ad sui investigationem hanc protestatem contulit intellectui, ut posssit coniuncta disiungere [...]. Abstrahens vero fidelis [est], et quasi quaedam officina omnium artium [...]. Licet enim esse nequeat homo qui non sit iste vel alius homo, intelligi tamen potest et significari ita quod nec intelligatur nec significetur iste vel alius. Ergo [...] per abstrahentem intellectum genera concipiantur et species, quae tamen si quis in rerum natura diligentius a sensibilibus remota quaerat, nihil aget et frustra laborabit [...]. Ratio autem ea deprehendit, substantialem similitudinem rerum differentium pertractans apud se [...]. Quod autem universalia dicuntur esse substantialia singularibus, ad causam cognitionis referendum est, singulariumque naturam») ${ }^{21}$ Por lo dicho se desprende que no hay realidades universales, sino sólo cosas individuales. Los que buscan tales realidades universales no encuentran nada. Pierden su tiempo, buscando lo que no existe ( Nihil autem universale est nisi quod in singularibus invenitur; seorsum tamen a multis quaesitum est, sed tandem nihil invenerunt [...], quoniam seorsum a singularibus nihil est»). ${ }^{22}$ De modo rotundo concluye que el universal es el término o concepto que basándose en las semejanzas de muchas cosas singulares las significa en general («Ergo quod mens communiter significat, et aeque de multis verum est, indubitanter universale est $\rangle^{23}$ ). Y, dado el ambiente del medievo cristiano, no podía faltar una alusión a la Biblia, incluso para rechazar el realismo. En el Génesis se narra la creación de las cosas de todas las especies, pero no hay la más mínima alusión a la creación de los universales («In operibus sex dierum in genere suo bona singula creata memorantur, nec tamen creationis universalium mentio aliqua facta est»).$^{24}$ En resumen, Ios universales según Aristóteles son algo mental, pero en la realidad sólo existe lo particular («Ergo dumtaxat intelliguntur secundum Aristotilem universalia, sed in actu rerum nihil est quod sit universale ${ }^{25}$ ). En toda esta exposición se desprende un gran aprecio hacia Aristóteles por parte de Juan. Hablando de la filosofía en general decía que el de Estagira es el filósofo por antonomasia. («Porque igual que Urbe significa Roma, poeta, Virgilio, así también el nombre de filósofo, por deseo de quienes lo usan, se restringió a Aristóteles». ${ }^{26}$ Del mismo modo, ahora, se inclina por Aristóteles en su opinión sobre los universales, y de ningún modo por el agustinismo platonizante («ipsius tamen dogma in scrutinio universalium nequaquam sequimur, eo quod hic Peripateticorum principem Aristotilem dogmatis huius principem profitemur»). ${ }^{27} \mathrm{De}$ lo dicho podemos concluir con nuestro autor que aunque ignoremos la esencia de los universales («quid sint»), por lo menos podemos darnos cuenta cómo se forman

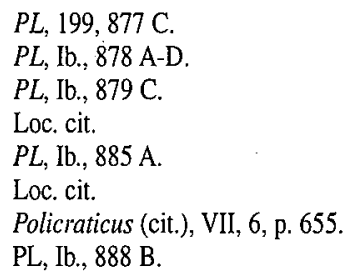


en nuestra inteligencia («Ergo [...] genera et species non onmino quid sunt, sed quale quid quodam modo concipiuntur». ${ }^{28}$

Aunque sea una poco reiterativa, recojo como colofón, la síntesis clarificadora que de esta problemática nos ofrece E. Gilson:

«El tipo de problema insoluble, para Juan de Salisbury, es el de los universales. No resulta sorprendente si pensamos que un tema se presta a la discusión filosófica tanto más cuanto su dificultad permite imaginar anticipadamente lo que se quiera. Así, pues, los filósofos se han apropiado este difícil tema y lo han discutido ampliamente; y, como empleaban las palabras al azar, han dado la impresión de sostener opiniones diferentes y han dejado a sus sucesores abundante materia de controversia. Por eso, en la actualidad contamos, por lo menos, con cinco soluciones al problema, tan viejo que el mundo mismo ha envejecido esforzándose por resolverlo, en el cual se ha perdido más tiempo del que emplearon los Césares en conquistar el dominio del mundo, y en el cual se ha gastado más dinero del que tuvo Creso. Según unos, los universales sólo existen en lo sensible y singular; otros conciben las formas como separadas, a modo de entes matemáticos; unos los hacen ya palabras, ya nombres, otros, por fin, identifican los universales con los conceptos. En realidad, ignoramos la manera de ser o el modo de existir de los universales; se puede decir, empero, ya que no cuál es su condición real, sí al menos de qué manera los adquirimos. La doctrina aristotélica de la abstracción nos permite resolver este segundo problema, más modesto que el primero. Buscar el modo de existencia actual de los universales considerados como cosas es una tarea infinita y poco fructífera; pero investigar lo que son en el entendimiento es una especulación fácil y útil. Efectivamente, se consideramos la semejanza sustancial de individuos numéricamente diferentes, obtendremos la especie; si examinamos después las semejanzas que subsisten entre especies diferentes, tendremos el género. Por consiguiente, alcanzamos los universales despojando, mediante el pensamiento, a las sustancias de las formas y de los accidentes por los que difieren. Si no existen individualmente, hay, por lo menos, posibilidad de pensarlos individualmente y de estudiar aparte estos universales que no existen aparte». ${ }^{29}$

César Raña Dafonte Universidad de Santiago de Compostela Depto. de Filosofía y Antropología Social 15706 SANTIAGO DE COMPOSTELA 